\title{
Using bond-length-dependent transferable force constants to predict vibrational entropies in Au-Cu, Au-Pd, and Cu-Pd alloys
}

\author{
Eric J. Wu and Gerbrand Ceder* \\ Department of Materials Science and Engineering, Massachusetts Institute of Technology, Cambridge, Massachusetts 02139 \\ Axel van de Walle \\ Department of Materials Science and Engineering, Northwestern University, Evanston, Illinois 60208 \\ (Received 26 July 2002; revised manuscript received 10 October 2002; published 7 April 2003)
}

\begin{abstract}
A model is tested to rapidly evaluate the vibrational properties of alloys with site disorder. It is shown that length-dependent transferable force constants exist and can be used to accurately predict the vibrational entropy of substitutionally ordered and disordered structures in $\mathrm{Au}-\mathrm{Cu}, \mathrm{Au}-\mathrm{Pd}$, and $\mathrm{Cu}-\mathrm{Pd}$. For each relevant force constant, a length-dependent function is determined and fitted to force constants obtained from firstprinciples pseudopotential calculations. We show that these transferable force constants can accurately predict vibrational entropies of $\mathrm{L}_{2}$-ordered and disordered phases in $\mathrm{Cu}_{3} \mathrm{Au}, \mathrm{Au}_{3} \mathrm{Pd}, \mathrm{Pd}_{3} \mathrm{Au}, \mathrm{Cu}_{3} \mathrm{Pd}$, and $\mathrm{Pd}_{3} \mathrm{Au}$. In addition, we calculate the vibrational entropy difference between $\mathrm{L}_{2}$-ordered and disordered phases of $\mathrm{Au}_{3} \mathrm{Cu}$ and $\mathrm{Cu}_{3} \mathrm{Pt}$.
\end{abstract}

DOI: 10.1103/PhysRevB.67.134103

PACS number(s): 64.75.+g, 63.20.-e, 65.20.+w

\section{INTRODUCTION}

In the last decade, a clear prescription has emerged to obtain phase diagrams of materials from first principles. When two compounds mix, some amount of site disorder occurs. First-principles alloy theory has been mostly preoccupied with defining appropriate energy models for such partially disordered systems and obtaining the parameters for them from increasingly accurate density functional theory (DFT) methods. In particular, the cluster expansion approach $^{1}$ has been highly successful, as it allows one to parametrize the energy of systems with disorder on a fixed framework of sites. Many binary phase diagrams have been calculated in this way. ${ }^{2-6}$

Most of these first-principles phase diagram calculations do not include vibrational entropy effects. The assumption that vibrational entropy differences between phases are small, and can therefore be neglected, has been recently examined experimentally ${ }^{7-11}$ and theoretically. ${ }^{12-18}$ In $\mathrm{Al}_{2} \mathrm{Cu}$ (Ref. 18) vibrational entropy contributions were shown to be essential in reversing the stability of $\theta$ and $\theta^{\prime}$ phases at finite temperatures. In the Al-Sc system, vibrational entropy contributions were shown to increase the solubility limits 27-fold. ${ }^{16,17}$

For alloys with partial site disorder, vibrational entropy in first-principles phase diagrams is computationally intensive to determine. In conventional first-principles alloy theory, a cluster expansion has to be fit to the ground state energies of a large number of $A-B$ ordered states (for a binary alloy). Vibrational effects can be formally included by fitting to vibrational free energies, rather than ground-state energies. ${ }^{19}$ This requires that one determine the phonon spectrum for many configurations. Unfortunately, this is computationally expensive.

One idea that has been proposed to alleviate this problem is the use of force constants that can be transferred between different environments. The existence of transferable force constants would greatly reduce the number of calculations required to determine vibrational entropies from first principles: currently, almost all of the work in calculating vibrational entropies is involved with the numerical determination of force constants for every environment in a large number of structures.

The idea of using transferable force constants to reduce computational expense is tremendously appealing. Despite this, until recently, there has been little clear evidence supporting the validity of their use. For instance, experimental data in $\mathrm{Fe}_{3} \mathrm{Al}$ show that force constants can have a clear configurational dependence. ${ }^{20}$ Strictly speaking, it is not possible to rigorously define configuration-independent force constant matrices as the form of the force constant matrix depends on the symmetry of the configuration. ${ }^{21}$ Nevertheless, configuration-independent transferable force constants have been used in computations to study segregation in $\mathrm{Ni}_{3} \mathrm{Al}$ (Ref. 22) and elastic properties in Li-Al (Ref. 23). In $\mathrm{Li}-\mathrm{Al}$, these force constants predicted elastic constants well, but reproduced vibrational entropies poorly. Transferable force constants have also been explored in oxides ${ }^{24}$ and semiconductors. ${ }^{25}$ In these materials, transferability is examined in the short-ranged force constants, which are obtained after subtracting out an analytical long-ranged dipole-dipole contribution. None of these studies examined the use of transferable force constants to calculate vibrational entropy. This is a challenging issue, as vibrational entropy differences between structures are a fraction of the total vibrational entropy and, hence, high relative accuracy is required.

Previous attempts at defining transferable force constant matrices $^{23}$ defined force constant matrices for a given pair type. Recently, it was shown that high accuracy in predicting the vibrational entropy could be achieved by using bondlength-dependent transferable force constants. ${ }^{12,26}$ This simple bond-length-dependent force constant model was shown to work well in predicting vibrational entropies in $\mathrm{Ni}_{3} \mathrm{Al}$ and $\mathrm{Pd}_{3} \mathrm{~V} .{ }^{12,13}$ The force constants were found to be 
transferable between different fcc structures at a single composition; their transferability between configurations with different atomic ratios or different chemical systems was untested.

In this paper, we evaluate the accuracy of the lengthdependent transferable force constants approach in calculating vibrational entropies in the $\mathrm{Au}-\mathrm{Cu}, \mathrm{Au}-\mathrm{Pd}$, and $\mathrm{Cu}-\mathrm{Pd}$ systems and also investigate the transferability of such relations between different chemical systems. Our results show that in the $\mathrm{Au}-\mathrm{Cu}, \mathrm{Au}-\mathrm{Pd}$, and $\mathrm{Cu}-\mathrm{Pd}$ systems, transferable force constants can be defined that depend on length and pair type. We show that these force constants can be exchanged between different structures and chemical systems, while still retaining good accuracy for calculating the vibrational entropy of intermetallic structures.

\section{METHODOLOGY}

A supercell method was used to calculate force constants. ${ }^{12,26-29}$ This method consists of creating a series of supercells with well-chosen displacements, calculating the resulting forces on atoms, and then using a least-squares fit to obtain the force constants. All total energy and force calculations were performed using the Vienna $a b$ initio simulation package (VASP) ${ }^{30,31}$ which implements Blöchl's projector augmented wave (PAW) approach ${ }^{32,33}$ within the local density approximation (LDA). The calculations used energy cutoffs of 300-400 eV and $\sim 150-200$ unique $\vec{k}$ points per 4 atoms. This resulted in energies converged to $\sim 5 \mathrm{meV}$ and forces converged to $1 \%$. Special care was taken to make sure forces on the initial structure vanished before supercell configurations were generated for the force constant calculation.

The superstructures and their perturbations were determined using an efficient algorithm, ${ }^{26}$ which generates supercells with perturbed atoms and their corresponding set of linear equations. Third-order anharmonic terms, which are present when positive and negative displacements are not symmetrically equivalent, were eliminated by subtracting forces taken from calculations of perturbations of equal magnitude but opposite sign. ${ }^{26}$ Vibrational entropy calculations were converged to within $0.015 k_{B}$ : this value is obtained by calculating the configuration-dependent part of the hightemperature limit of the vibrational entropy per atom, $S_{v i b}$ $=-k_{B} \int_{0}^{\infty} g(\omega) \ln \omega d \omega$, for increasing force constant range until $S_{v i b}$ changed by less than $0.015 k_{B}$. Typically, this requires $\sim 4-5$ neighbors for $\mathrm{L}_{2}$ structures and 2 neighbors for SQS-8 structures.

The above procedure was applied to calculate vibrational entropies of $\mathrm{L1}_{2}$-ordered and disordered phases in the $\mathrm{Au}_{3} \mathrm{Cu}, \mathrm{Cu}_{3} \mathrm{Au}, \mathrm{Au}_{3} \mathrm{Pd}, \mathrm{Pd}_{3} \mathrm{Au}, \mathrm{Cu}_{3} \mathrm{Pd}, \mathrm{Pd}_{3} \mathrm{Au}$, and $\mathrm{Cu}_{3} \mathrm{Pt}$ systems. In addition, we calculated vibrational entropies of $\mathrm{L1}_{2}$-ordered $\mathrm{Ag}_{3} \mathrm{Au}$ and $\mathrm{Au}_{3} \mathrm{Ag}$. The disordered structure was approximated by an 8 -atom special quasirandom structure (SQS) ${ }^{34}$ These structures have been shown to give the best possible approximation to a disordered structure, within a given number of sites. In $\mathrm{Ni}_{3} \mathrm{Al}$, Morgan et al. tested the convergence of vibrational properties with SQS size and found that a SQS with 8 atoms is a good approximation of the disordered state. ${ }^{35}$ The SQS- 8 used in this study has been used successfully in first-principles vibrational entropy calculations of disordered $\mathrm{Ni}_{3} \mathrm{Al}$ and $\mathrm{Pd}_{3} \mathrm{~V}{ }^{12,13}$

To define transferable force constant matrices, some approximations are necessary. The form of a force constant matrix, and hence the number of nonzero force constants, depends on the symmetry of structure. In this work, we use a stretching-bending force constant model. In this model, the coordinate system of each force constant matrix is transformed, so that the $z$ axis is aligned along the segment joining the two atoms in question. Two further approximations are necessary to obtain transferable force constants. First, bending terms are averaged, so that they are orientation independent. Second, off-diagonal terms are constrained to be zero. The resulting force constant matrix has only two independent terms $-\mathrm{a}$ stretching term $s$ and a bending term $b$-and the form of the matrix can be written

$$
\left(\begin{array}{lll}
b & 0 & 0 \\
0 & b & 0 \\
0 & 0 & s
\end{array}\right) .
$$

The stretching term $(s)$ can be used as a qualitative measure of the bond strength. However, it is not possible to keep only the stretching terms $(s)$ in the force constant matrix: doing so can result in large errors $\left(0.2 k_{B}\right)$ in the vibrational entropy. ${ }^{12,26} \mathrm{We}$ examined two types of errors associated with using stretching-bending force constant matrices: errors introduced in the force constants and errors introduced in the vibrational entropy. For all force constant matrices examined, the rms error associated with constraining the bending terms to be equal was $0.052 \mathrm{eV} / \mathrm{A}^{2}$ per bending term. The rms error associated with setting off-diagonal terms to zero was $0.009 \mathrm{eV} / \mathrm{A}^{2}$ per off-diagonal term. Stretching terms contain no errors associated with the stretching-bending force constant model: they are directly obtained from the coordinate transformation, with no further approximations.

The errors introduced into the vibrational entropy by using the stretching-bending force constant model are shown in Table I. For 14 out of the 16 structures tested, $S_{v i b}$ calculated using full-force constant matrices and $S_{v i b}$ calculated using the stretching-bending force constant model agreed to within $0.01 k_{B}$. For the $\mathrm{L}_{2} \mathrm{Au}_{3} \mathrm{Cu}$ structure, the stretching-bending force constant approximation failed when using nearestneighbor force constants; for the SQS- $8 \mathrm{Au}_{3} \mathrm{Cu}$ structure, the stretching-bending force constant approximation failed when using both nearest-neighbor and all-neighbor force constants (where "all-neighbor" is defined as the force constant range at which vibrational entropies were converged to within $\left.0.015 k_{B}\right)$. In these structures, using stretching-bending force constant matrices resulted in a dynamically unstable structure. Tests of each approximation revealed that the negative phonon modes in the $\mathrm{L}_{2} \mathrm{Au}_{3} \mathrm{Cu}$ structure arise because the off-diagonal terms to set to zero; negative phonon modes in the SQS-8 $\mathrm{Au}_{3} \mathrm{Cu}$ arise due to both the neglect of the offdiagonal terms and the constraint on the bending terms. In previous work, the errors in vibrational entropy by using the simplified stretching-bending force constant model have been tested for five structures in the $\mathrm{Ni}_{3} \mathrm{Al}$ and $\mathrm{Pd}_{3} \mathrm{~V}$ 
TABLE I. Vibrational entropy data. Listed are vibrational entropies calculated with all-neighbors and full-force constant matrices, vibrational entropies calculated with all-neighbors and stretching-bending force constants, calculated vibrational entropy with first nearestneighbor and full-force constant matrices, calculated vibrational entropy with first-neighbor and stretching-bending force constant matrices, and fit-vibrational entropies using first-neighbor and stretching-bending force constants. Also listed is $\left(S_{v i b}^{\text {calc,all}}-S_{v i b}^{f i t, 1 N N}\right)$, the error introduced by using fit force constants, the stretching-bending force constant model, and first nearest-neighbor force constants. Errors are $0.015 k_{B}$ unless otherwise indicated. All numbers are rounded to $0.01 k_{B}$.

\begin{tabular}{|c|c|c|c|c|c|c|c|}
\hline Structure & $\begin{array}{l}\text { Neighbors } \\
\text { used in full- } \\
\text { force constant } \\
\text { calculation }\end{array}$ & $\begin{array}{l}S_{v i b}^{c a l c, \text { all neigh }, \text { full } f c} \\
\text { Calculated, } \\
\text { all-neighbors, } \\
\text { full-force constants } \\
\qquad\left(k_{\mathrm{B}}\right)\end{array}$ & $\begin{array}{l}S_{v i b}^{c a l c, a l l} \text { neigh,sb } \\
\text { Calculated, } \\
\text { all-neighbors, } \\
\text { stretching and } \\
\text { bending force } \\
\text { constants }\left(k_{\mathrm{B}}\right)\end{array}$ & $\begin{array}{c}S_{v i b}^{c a l c, 1 N N, f u l l} f_{c} \\
\text { Calculated, } \\
1 \mathrm{NN}, \\
\text { full-force } \\
\text { constants } \\
\left(k_{\mathrm{B}}\right)\end{array}$ & $\begin{array}{l}S_{v i b}^{c a l c, 1 N N, s b} \\
\text { Calculated, } \\
1 \mathrm{NN}, \text { stretching } \\
\text { and bending } \\
\text { force constants } \\
\qquad\left(k_{\mathrm{B}}\right)\end{array}$ & $\begin{array}{l}S_{v i b}^{f i t, 1 N N, s b} \\
\text { Fit, 1NN, } \\
\text { stretching and } \\
\text { bending term } \\
\text { force constants } \\
\quad\left(k_{\mathrm{B}}\right)\end{array}$ & $\begin{array}{l}\left(S_{v i b}^{\text {calc,all neigh, full } f c}\right. \\
\left.\quad-S_{\text {vib }}^{f i t, 1 N N, s b}\right)\end{array}$ \\
\hline $\mathrm{Pd}_{3} \mathrm{Cu} \mathrm{L} 1_{2}$ & 5 & -4.56 & -4.55 & -4.59 & -4.59 & -4.57 & +0.01 \\
\hline $\mathrm{Pd}_{3} \mathrm{Cu}$ SQS8 & 2 & -4.53 & -4.53 & -4.53 & -4.53 & -4.55 & +0.02 \\
\hline $\mathrm{Pd}_{3} \mathrm{Au} \mathrm{L1} 1_{2}$ & 3 & -4.23 & -4.23 & -4.21 & -4.21 & -4.17 & -0.06 \\
\hline $\mathrm{Pd}_{3} \mathrm{Au}$ SQS8 & 2 & -4.16 & -4.16 & -4.15 & -4.15 & -4.15 & -0.01 \\
\hline $\mathrm{Cu}_{3} \mathrm{Pd} \mathrm{L1}{ }_{2}$ & 3 & -4.73 & -4.72 & -4.70 & -4.70 & -4.76 & -0.03 \\
\hline $\mathrm{Cu}_{3} \mathrm{Pd}$ SQS8 & 2 & -4.76 & -4.76 & -4.76 & -4.76 & -4.76 & -0.00 \\
\hline $\mathrm{Cu}_{3} \mathrm{Au} \mathrm{L} 1_{2}$ & 3 & -4.31 & -4.30 & -4.28 & -4.27 & -4.28 & -0.03 \\
\hline $\mathrm{Cu}_{3} \mathrm{Au}$ SQS8 & 2 & $-4.24(0.03)$ & -4.24 & -4.27 & -4.27 & -4.27 & +0.04 \\
\hline $\mathrm{Au}_{3} \mathrm{Pd} \mathrm{L1} 1_{2}$ & 5 & -3.40 & -3.40 & -3.42 & -3.41 & -3.40 & +0.00 \\
\hline $\mathrm{Au}_{3} \mathrm{Pd}$ SQS8 & 2 & -3.45 & -3.45 & -3.45 & -3.45 & -3.40 & -0.05 \\
\hline $\mathrm{Au}_{3} \mathrm{Cu} \mathrm{L} 1_{2}$ & 5 & -3.24 & -3.21 & -3.21 & unstable & & \\
\hline $\mathrm{Au}_{3} \mathrm{Cu}$ SQS8 & 2 & -3.25 & unstable & -3.24 & unstable & & \\
\hline $\mathrm{Cu}_{3} \mathrm{Pt} \mathrm{L1} 1_{2}$ & 3 & -4.54 & -4.53 & -4.52 & -4.51 & & \\
\hline $\mathrm{Cu}_{3} \mathrm{Pt}$ SQS8 & 2 & -4.52 & -4.51 & -4.51 & -4.50 & & \\
\hline $\mathrm{Ag}_{3} \mathrm{Au} \mathrm{L1}{ }_{2}$ & 3 & -3.57 & -3.56 & -3.55 & -3.54 & & \\
\hline $\mathrm{Au}_{3} \mathrm{Ag} \mathrm{L1}{ }_{2}$ & 2 & -3.17 & -3.17 & -3.13 & -3.13 & & \\
\hline
\end{tabular}

system. ${ }^{12,13}$ In those systems, the errors on vibrational entropy for all structures were less than $0.01 k_{B}$ /atom.

\section{RESULTS AND DISCUSSION}

Calculated vibrational entropies for all structures examined in the $\mathrm{Ag}-\mathrm{Ag}, \mathrm{Au}-\mathrm{Cu}, \mathrm{Au}-\mathrm{Pd}, \mathrm{Cu}-\mathrm{Pt}$, and $\mathrm{Cu}-\mathrm{Pd}$ system are listed in Table I. For the $\mathrm{Cu}-\mathrm{Au}$ system, our results can be compared with previous experimental ${ }^{10,36}$ and theoretical ${ }^{14}$ work. We calculated $S_{v i b}(\mathrm{Cu})=4.87 k_{B}$ and $S_{v i b}(\mathrm{Au})$ $=2.85 k_{B}$, which yields for the formation entropies $S_{v i b}^{f o r m}\left(\mathrm{~L} 1_{2} \mathrm{Cu}_{3} \mathrm{Au}\right)=0.10 k_{B} \quad$ and $\quad S_{v i b}^{\text {form }}\left(\mathrm{L1}_{2} \mathrm{Au}_{3} \mathrm{Cu}\right)$ $=0.11 k_{B}$. Our calculated $S_{v i b}^{\text {form }}\left(\mathrm{L1}_{2} \mathrm{Cu}_{3} \mathrm{Au}\right)$ agrees well with previous experimental work, which found $S_{v i b}^{\text {form }}\left(\mathrm{L} 1_{2} \mathrm{Cu}_{3} \mathrm{Au}\right)=(0.07 \pm 0.03) k_{B} \cdot{ }^{36}$ Our calculated formation entropies also agree well with previous theoretical work, which found $S_{\text {vib }}^{\text {form }}\left(\mathrm{L}_{2} \mathrm{Cu}_{3} \mathrm{Au}\right)=0.10 k_{B}$ and $S_{\text {vib }}^{\text {form }}\left(\mathrm{L}_{2} \mathrm{Au}_{3} \mathrm{Cu}\right)=0.14 k_{B} \cdot{ }^{14}$ The entropy change upon disordering in $\mathrm{Cu}_{3} \mathrm{Au}\left[\Delta S_{\text {vib }}^{\text {order } \rightarrow \text { disorder }}\left(\mathrm{Cu}_{3} \mathrm{Au}\right)\right]$ is calculated to be $(0.07 \pm 0.045) k_{B}$. This value is lower than the experimental value of $(0.14 \pm 0.05) k_{B} \cdot{ }^{10}$ However, this calculation is in good agreement with previous theoretical work, in which $\Delta S_{\text {vib }}^{\text {order } \rightarrow \text { disorder }}\left(\mathrm{Cu}_{3} \mathrm{Au}\right)=0.08 k_{B}$ was obtained. ${ }^{14}$ For $\mathrm{Au}_{3} \mathrm{Cu}$, we calculate $\Delta S_{\text {vib }}^{\text {order } \rightarrow \text { disorder }}\left(\mathrm{Au}_{3} \mathrm{Cu}\right)$ $=(-0.01 \pm 0.03) k_{B}$, which is lower than the previously calculated $\Delta S_{\text {vib }}^{\text {order } \rightarrow \text { disorder }}\left(\mathrm{Au}_{3} \mathrm{Cu}\right)=0.05 k_{B} \cdot{ }^{14}$

Calculated full-force constant matrices were transformed to the stretching-bending force constant model, with the results plotted in Figs. 1-6. The different bond lengths correspond to equilibrium bond lengths in various structures. For all pair types, the force constant stiffness for both stretching and bending terms decreases with increasing bond length. In particular, the stiffness of first nearest-neighbor force constant matrices shows a strong dependence on bond length. This dependence of bond stiffness on bond length shows that

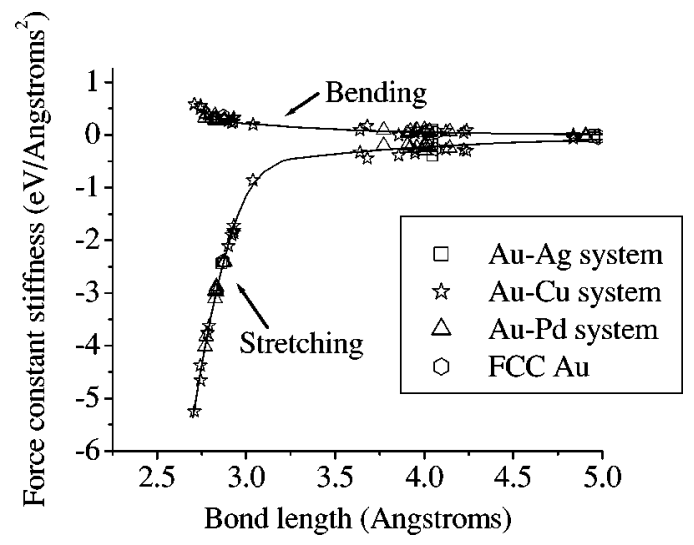

FIG. 1. Stiffness of bending and stretching force constants vs bond length for $\mathrm{Au}-\mathrm{Au}$ bonds. Force constants for the same system are represented by the same symbol (for example, all Au-Au bonds for $L 1_{2} \mathrm{Au}_{3} \mathrm{Cu}$ use the same symbol). Lines are drawn as guides to the eye. 


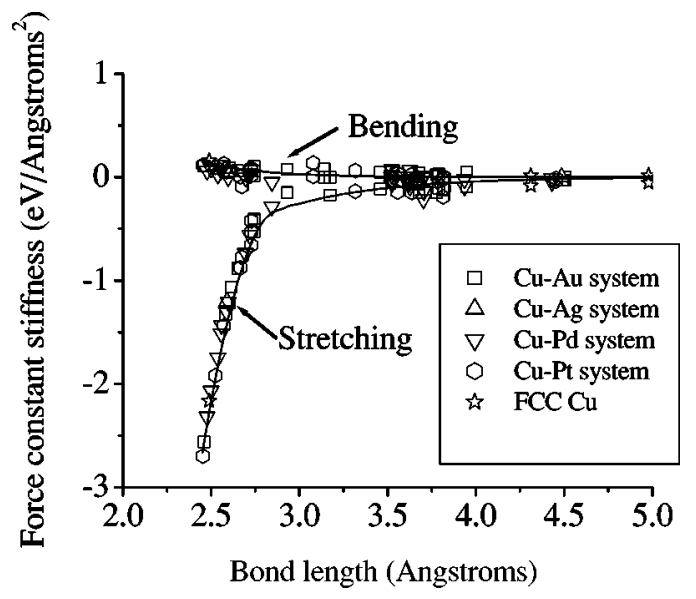

FIG. 2. Stiffness of bending and stretching force constants vs bond length for $\mathrm{Cu}-\mathrm{Cu}$ bonds. Lines are drawn as guides to the eye.

one cannot rely too much upon simple bond-counting $\operatorname{arguments}^{26}$ when predicting or explaining vibrational entropy differences between phases because the bond-counting effect does not take into account bond length changes upon disordering. Figures 1-6 show that small changes in bond length upon disordering can have a large effect on force constants and vibrational entropy. The relationship between atomic relaxations and vibrational entropy has been previously noted. ${ }^{12,16-18}$

For a given bond type, stretching and bending force constants for all systems and structures are found to lie on a single curve. Thus, the dependence of bond stiffness on ordering, composition, or chemical system can be explained almost entirely in terms of bond length changes. Remarkably, other effects on force constant stiffness, such as changes in charge density associated with different configurations and chemical systems, are small. This may be because our study is limited to noble-metal intermetallics.

For each pair type, we constructed a relationship between force constant stiffness and bond length. Our goal is to parametrize the stiffness of the stretching and bending force constants as a function of bond length and then use "fitted" force constants from these functions to predict vibrational entropy. Stretching terms were fit to a second-order polyno-

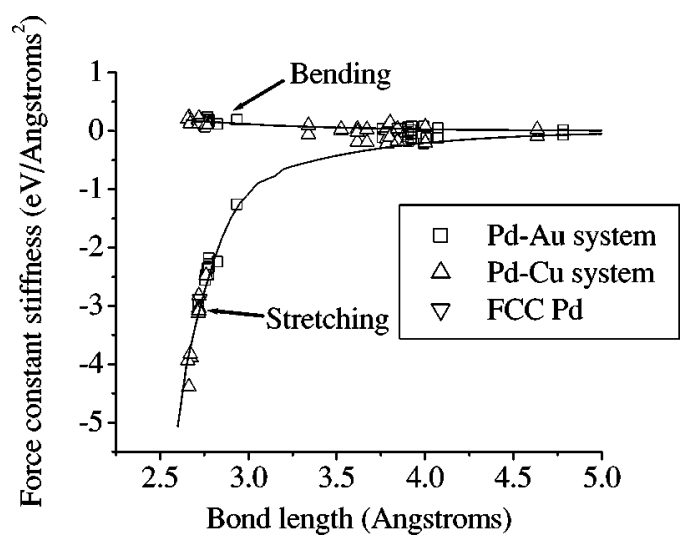

FIG. 3. Stiffness of bending and stretching force constants vs bond length for Pd-Pd bonds. Lines are drawn as guides to the eye.

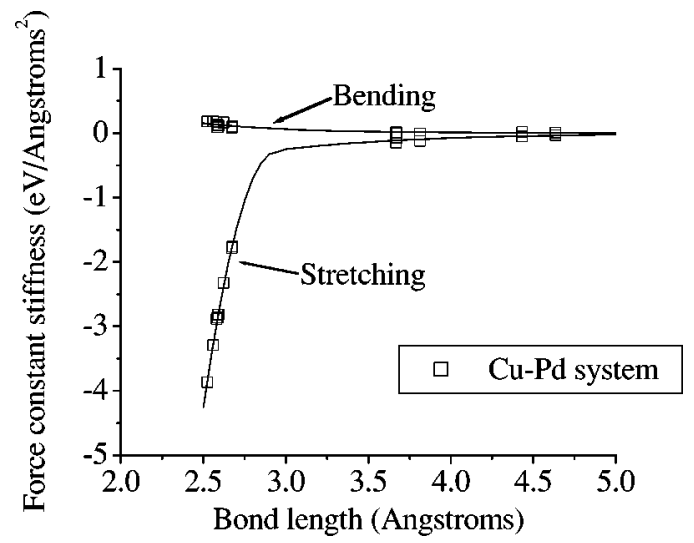

FIG. 4. Stiffness of bending and stretching force constants vs bond length for $\mathrm{Cu}-\mathrm{Pd}$ bonds. Lines are drawn as guides to the eye.

mial; bending terms were fit to a linear function. The fit was restricted to first-nearest-neighbor force constants. The rms fitting error over all stretching terms was $0.102 \mathrm{eV} / \mathrm{A}^{2}$; the $\mathrm{rms}$ fitting error over all bending terms was $0.048 \mathrm{eV} / \mathrm{A}^{2}$.

Although attempts to use longer-ranged fitted force constants were unsuccessful, the errors introduced by using only nearest-neighbor force constants were small. In the systems studied, vibrational entropy converged quickly with respect to neighbors: the difference between $S_{v i b}$ calculated using only first nearest neighbors and $S_{v i b}$ calculated using all neighbors was typically around $\sim(0.00-0.02) k_{B}$, with a maximum difference of $0.03 k_{B}$ in $\mathrm{L}_{2} \mathrm{Pd}_{3} \mathrm{Cu}$. Previous studies on intermetallics and group-IV semiconductors have also shown that vibrational entropy can converge quickly with respect to neighbors. ${ }^{12,13,37}$

The results of using fitted force constants to predict vibrational entropies are shown in Table I. For all structures, the vibrational entropies obtained using fitted force constants agree well with the vibrational entropies obtained using directly calculated force constants. The rms error between $S_{v i b}^{\text {calc, all neigh,full } f c}$ and $S_{v i b}^{f i t, 1 N N, s b}$ for all structures investigated was $0.032 k_{B}$, with a maximum error of $0.058 k_{B}$ in $\mathrm{L}_{2} \mathrm{Pd}_{3} \mathrm{Au}$. The errors are $\sim 1 \%-2 \%$ of the absolute vibrational entropy. These calculations show the predictive power

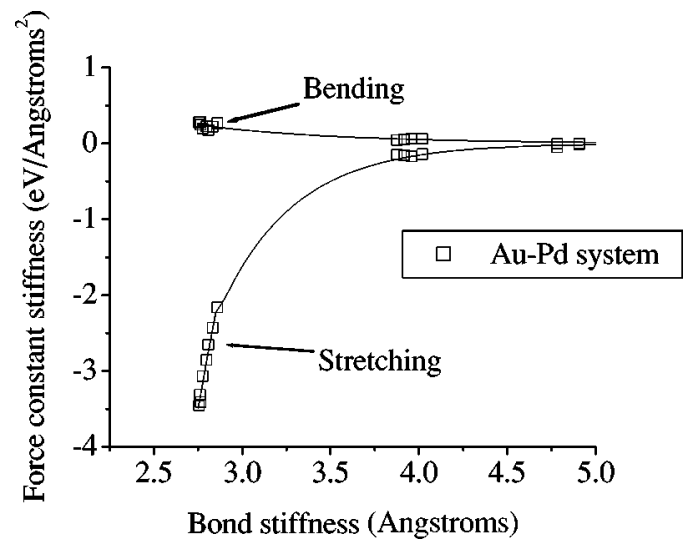

FIG. 5. Stiffness of bending and stretching force constants vs bond length for Au-Pd bonds. Lines are drawn as guides to the eye. 


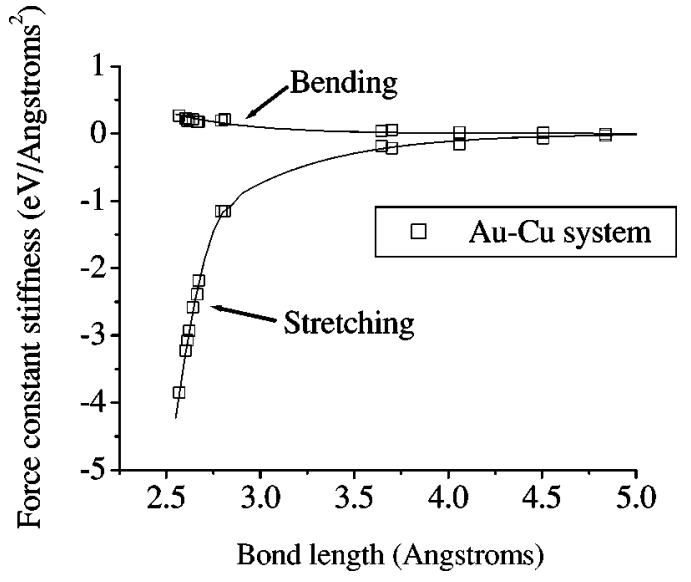

FIG. 6. Stiffness of bending and stretching force constants vs bond length for $\mathrm{Au}-\mathrm{Cu}$ bonds. Lines are drawn as guides to the eye.

of using fitted stretching-bending force constants to predict vibrational entropies.

We also tested the accuracy of using fitted force constants, in representing the effect of homogeneous volume changes. In metals, pairwise expansion can usually not capture the effect of such electron density changes of the energy. The force constants and vibrational entropy of $\mathrm{L}_{2}$ and SQS-8 structures for $\mathrm{Pd}_{3} \mathrm{Cu}, \mathrm{Pd}_{3} \mathrm{Au}, \mathrm{Cu}_{3} \mathrm{Pd}, \mathrm{Cu}_{3} \mathrm{Au}$, and $\mathrm{Au}_{3} \mathrm{Pd}$ were recalculated at a volume $\sim 2 \%$ larger than the equilibrium volume. For the $L 1_{2} \operatorname{Pd}_{3} \mathrm{Cu}$ structure, the vibrational entropies at a $4 \%$ and $6 \%$ volume increase were also calculated. These direct results were then compared with predicted results obtained from using force constants derived from equilibrium volume calculations. None of the force constants at these increased volumes were included in the fit. The results of using these fitted force constants to predict vibrational entropy are shown in Table II. For all structures at 2\% increased volume, the rms error between $S_{v i b}^{c a l c, \text { all neigh, full } f c}$ and $S_{v i b}^{f i t, 1 N N, s b}$ was $0.033 k_{B}$, with a maximum error of $0.053 k_{B}$ in $\mathrm{Ll}_{2} \mathrm{Pd}_{3} \mathrm{Au}$. Thus, even when the force constant data are not included in the fit, the length-dependent force constant function gives force constants that accurately predict vibrational entropies.

Often, one is interested in vibrational entropy differences, rather than absolute vibrational entropies. We used vibrational entropy data from Tables I and II to obtain two types of vibrational entropy differences that are of interest: the vibrational entropy difference between ordered and disordered phases and vibrational entropy difference between a structure at two volumes separated by $\sim 2 \%$. The latter is related to the thermal expansion by the expression $\alpha_{L}$ $=\Delta S /(3 B \Delta V)$, where $B$ is the bulk modulus. These data are shown in Table III. In the systems studied, we estimated the effect of vibrations on calculated phase boundaries by using the following procedure: The change in transition temperature when vibrations are included in the phase diagram calculation is given by $T_{\text {config }+ \text { vib }}^{\alpha \rightarrow \beta}=T_{\text {configonly }}^{\alpha \rightarrow \beta}$ ( 1 $\left.+\Delta S_{v i b}^{\alpha \rightarrow \beta} / \Delta S_{\text {config }}^{\alpha \rightarrow \beta}\right){ }^{14}$ Thus, $\Delta S_{v i b}^{\alpha \rightarrow \beta} / \Delta S_{\text {config }}^{\alpha \rightarrow \beta}$ determines the effect of lattice vibrations on calculated phase diagrams. The configurational entropy per atom for a binary solid solution depends on the state of short-range order. It has a maximum value for an ideal (random) solution of $S_{\text {config }}^{\alpha}$ $=k[c \ln c+(1-c) \ln (1-c)]$. Hence, the maximum value of $\Delta S_{\text {config }}^{\alpha \rightarrow \beta}$ in the systems studied is $0.562 k_{B}$ /atom: this value occurs when a fully ordered state $\left(S_{\text {config }}^{\alpha}=0\right)$ at $c=0.25$ transforms to a fully random solid solution. In most cases, the actual value of $\Delta S_{\text {config }}^{\alpha \rightarrow \beta}$ will be smaller than this, owing to short-range order in the disordered state and also some disorder in the low-temperature phase. Nevertheless, our approximate estimate shows that phase boundaries in the systems studied would change by $\sim 5 \%-13 \%$ if vibrations were included.

The data in Table III can be used to examine the ability of

TABLE II. Vibrational entropies at increased volume Percentage increase in volume is indicated in parentheses. Listed are vibrational entropies calculated with all neighbors and full-force constant matrices, vibrational entropies calculated with fit first-nearest-neighbor stretching-bending force constants, and $\left(S_{v i b}^{\text {calc,all neigh,full fc }}-S_{v i b}^{f i t, 1 N N, s b}\right)$. All numbers are rounded to $0.01 k_{B}$.

\begin{tabular}{|c|c|c|c|c|c|}
\hline Structure & $\begin{array}{l}\text { Neighbors used in } \\
\text { full-force constant } \\
\text { calculation }\end{array}$ & $\begin{array}{l}S_{v i b} \\
\text { All neighbors, full- } \\
\text { force constants }\left(k_{\mathrm{B}}\right)\end{array}$ & $\begin{array}{c}S_{v i b}^{1 N N} \\
1 \mathrm{NN}, \text { full-force } \\
\text { constants } \\
\left(k_{\mathrm{B}}\right)\end{array}$ & $\begin{array}{c}S_{v i b}^{f i t, 1 N N} \\
\text { Fit stretching and } \\
\text { bending terms, 1NN } \\
\left(k_{\mathrm{B}}\right)\end{array}$ & $\left(S_{v i b}^{c a l c, a l l}-S_{v i b}^{f i t, 1 N N}\right)$ \\
\hline $\mathrm{Pd}_{3} \mathrm{Cu} \mathrm{L} 1_{2}(2 \%)$ & 5 & -4.41 & -4.44 & -4.42 & 0.01 \\
\hline $\mathrm{Pd}_{3} \mathrm{Cu} \mathrm{L} 1_{2}(4.5 \%)$ & 5 & -4.30 & -4.33 & -4.31 & 0.01 \\
\hline $\mathrm{Pd}_{3} \mathrm{Cu} \mathrm{L} 1_{2}(6.0 \%)$ & 5 & -4.14 & -4.17 & -4.16 & 0.02 \\
\hline $\mathrm{Pd}_{3} \mathrm{Cu}$ SQS8 $(2 \%)$ & 2 & -4.39 & -4.37 & -4.40 & 0.01 \\
\hline $\mathrm{Pd}_{3} \mathrm{Au} \mathrm{L1} 1_{2}(2 \%)$ & 3 & -4.08 & -4.06 & -4.02 & -0.05 \\
\hline $\mathrm{Pd}_{3} \mathrm{Au}$ SQS $(2 \%)$ & 2 & -4.01 & -4.00 & -3.99 & -0.02 \\
\hline $\mathrm{Cu}_{3} \mathrm{Pd} \mathrm{L1} 1_{2}(2 \%)$ & 3 & -4.61 & -4.58 & -4.64 & +0.03 \\
\hline $\mathrm{Cu}_{3} \mathrm{Pd}$ SQS8 $(2 \%)$ & 2 & -4.63 & -4.62 & -4.62 & -0.01 \\
\hline $\mathrm{Cu}_{3} \mathrm{Au} \mathrm{L1} 1_{2}(2 \%)$ & 3 & -4.18 & -4.15 & -4.13 & -0.05 \\
\hline $\mathrm{Cu}_{3} \mathrm{Au}$ SQS8 $(2 \%)$ & 2 & -4.12 & -4.14 & -4.13 & +0.01 \\
\hline $\mathrm{Au}_{3} \mathrm{Pd} \mathrm{L} 1_{2}(2 \%)$ & 5 & -3.24 & -3.26 & -3.27 & +0.03 \\
\hline $\mathrm{Au}_{3} \mathrm{Pd}$ SQS8 $(2 \%)$ & 2 & -3.28 & -3.27 & -3.23 & -0.05 \\
\hline
\end{tabular}


TABLE III. Vibrational entropy differrences. Listed are vibrational entropy differences upon disordering and vibrational entropy differences between the same structure at different volumes. Percentage increase in volume is indicated in parentheses. Also shown are errors in differences, $\Delta S_{v i b}^{\text {calc,all neighbors }}-\Delta S_{\text {vib }}^{\text {fit }, 1 N N}$

\begin{tabular}{|c|c|c|c|}
\hline System & $\begin{array}{l}\qquad \Delta S_{v i b}^{\text {calc, all neighbors, full } f c} \\
\text { All-neighbors, full-force constants } \\
\qquad\left(k_{\mathrm{B}}\right)\end{array}$ & $\begin{array}{l}\Delta S_{v i b}^{f i t, 1 N N, s b} \\
\text { Fit stretching and bending } \\
\text { terms, } 1 \mathrm{NN}\left(k_{\mathrm{B}}\right)\end{array}$ & $\Delta S_{v i b}^{\text {calc,all neigh,full } f c}-\Delta S_{v i b}^{f i t, 1 N N, s b}$ \\
\hline $\mathrm{Pd}_{3} \mathrm{Cu} \mathrm{SQS} 8-\mathrm{Pd}_{3} \mathrm{Cu} \mathrm{L} 1_{2}$ & +0.03 & +0.05 & +0.02 \\
\hline $\mathrm{Pd}_{3} \mathrm{Au}$ SQS8 $-\mathrm{Pd}_{3} \mathrm{Au} \mathrm{L1}{ }_{2}$ & +0.07 & +0.02 & +0.05 \\
\hline $\mathrm{Cu}_{3} \mathrm{Pd} \mathrm{SQS} 8-\mathrm{Cu}_{3} \mathrm{Pd} \mathrm{L} 1_{2}$ & +0.03 & +0.00 & +0.03 \\
\hline $\mathrm{Cu}_{3} \mathrm{Au} \mathrm{SQS} 8-\mathrm{Cu}_{3} \mathrm{Au} \mathrm{L1}{ }_{2}$ & +0.07 & +0.00 & -0.06 \\
\hline $\mathrm{Au}_{3} \mathrm{Pd} \mathrm{SQS} 8-\mathrm{Au}_{3} \mathrm{Pd} \mathrm{L} 1_{2}$ & -0.05 & -0.04 & +0.01 \\
\hline $\mathrm{Pd}_{3} \mathrm{Cu} \mathrm{L1}{ }_{2}(2 \%)-\mathrm{Pd}_{3} \mathrm{Cu} \mathrm{L1} 1_{2}$ & +0.14 & +0.15 & +0.00 \\
\hline $\mathrm{Pd}_{3} \mathrm{Cu}$ SQS8 $(2 \%)-\mathrm{Pd}_{3} \mathrm{Cu}$ SQS8 & +0.14 & +0.15 & -0.01 \\
\hline $\mathrm{Pd}_{3} \mathrm{Au} \mathrm{L1} 1_{2}(2 \%)-\mathrm{Pd}_{3} \mathrm{Au} \mathrm{L1} 1_{2}$ & +0.15 & +0.15 & +0.01 \\
\hline $\mathrm{Pd}_{3} \mathrm{Au}$ SQS8 $(2 \%)-\mathrm{Pd}_{3} \mathrm{Au}$ SQS8 & +0.15 & +0.16 & -0.02 \\
\hline $\mathrm{Cu}_{3} \mathrm{Pd} \mathrm{L1}{ }_{2}(2 \%)-\mathrm{Cu}_{3} \mathrm{Pd} \mathrm{L1}_{2}$ & +0.12 & +0.12 & +0.00 \\
\hline $\mathrm{Cu}_{3} \mathrm{Pd} \mathrm{SQS} 8(2 \%)-\mathrm{Cu}_{3} \mathrm{Pd}$ SQS8 & +0.13 & +0.14 & -0.01 \\
\hline $\mathrm{Cu}_{3} \mathrm{Au} \mathrm{L1}{ }_{2}(2 \%)-\mathrm{Cu}_{3} \mathrm{Au} \mathrm{L1}_{2}$ & +0.12 & +0.15 & -0.02 \\
\hline $\mathrm{Cu}_{3} \mathrm{Au}$ SQS8 $(2 \%)-\mathrm{Cu}_{3} \mathrm{Au}$ SQS8 & +0.12 & +0.14 & -0.02 \\
\hline $\mathrm{Au}_{3} \mathrm{Pd} \mathrm{L1}{ }_{2}(2 \%)-\mathrm{Au}_{3} \mathrm{Pd} \mathrm{L1}{ }_{2}$ & +0.16 & +0.13 & -0.03 \\
\hline $\mathrm{Au}_{3} \mathrm{Pd} \mathrm{SQS} 8(2 \%)-\mathrm{Au}_{3} \mathrm{Pd} \mathrm{SQS} 8$ & +0.17 & +0.17 & +0.00 \\
\hline $\mathrm{Pd}_{3} \mathrm{Cu} \mathrm{L1} 1_{2}(4.5 \%)-\mathrm{Pd}_{3} \mathrm{Cu} \mathrm{L1} 1_{2}$ & +0.25 & +0.26 & +0.00 \\
\hline $\mathrm{Pd}_{3} \mathrm{Cu} \mathrm{L} 1_{2}(6.0 \%)-\mathrm{Pd}_{3} \mathrm{Cu} \mathrm{L} 1_{2}$ & +0.42 & +0.41 & +0.00 \\
\hline
\end{tabular}

transferable force constants to predict vibrational entropy differences. The rms error between calculated and fit differences $\left(\Delta S_{v i b}^{\text {calc, all neigh, full fc }}-\Delta S_{v i b}^{\text {fit }, 1 N N, s b}\right)$ was $0.030 k_{B}$, with a maximum error of $0.063 k_{B}$ in $\mathrm{Cu}_{3} \mathrm{Au}$. For vibrational entropy differences between structures at volumes $2 \%$ apart, the rms error between calculated and fit differences was $0.016 k_{B}$ with a maximum error of $0.030 k_{B}$ in $L 1_{2} \quad \mathrm{Au}_{3} \mathrm{Pd}$. Thus, the transferable force constants used here are able to predict vibrational entropy differences reasonably well.

In examining the data, one can make a few observations with respect to the accuracy of using transferable force constants. First, errors in absolute entropies from using transferable force constants (Tables I and II) were typically $\sim(0.00-0.05) k_{B}$ for all structures. This was true for structures with both large and small absolute vibrational entropies. Second, in all cases, the transferable force constants were able to correctly predict the relative hierarchy of entropy differences. Thus, large entropy differences are predicted to be large; small entropy differences are predicted to be small. A small entropy difference was never predicted to be large, or vice versa. Third, when using transferable force constants, errors in entropy differences between the same structure at different volumes tended to cancel; errors in entropy differences between different structures (at the same composition) did not tend to cancel as much (Table III). Thus, it is likely that there are small structure-dependent contributions to the force constant stiffness that are not captured by our length-dependence force constant model. Fourth, using transferable force constants gave small absolute errors in vibrational entropy differences $\left[\sim(0.00-0.07) k_{B}\right]$. For small vibrational entropy differences, this sometimes resulted in $\sim 15 \%-20 \%$ errors, whereas the percentage errors in larger vibrational entropy differences were smaller. Last, this method can greatly reduce the computational cost of calculating vibrational properties of intermetallics.

\section{CONCLUSION}

The vibrational entropies for 16 structures in the Ag-Au, $\mathrm{Au}-\mathrm{Cu}, \mathrm{Au}-\mathrm{Pd}, \mathrm{Cu}-\mathrm{Pd}$, and $\mathrm{Cu}-\mathrm{Pt}$ systems have been calculated. A simplified model was used with only stretching and bending terms, making the force constant matrices independent of symmetry. With these approximations, the form of the force constant matrices was independent of crystal symmetry. We found that the variation of force constants with ordering, composition, or chemical system can be explained almost entirely through changes in bond length. This method represents a promising way to include vibrational effects in phase diagram calculations at a moderate computational cost.

\section{ACKNOWLEDGMENTS}

This work was supported by the Department of Energy, Office of Basic Energy Sciences, under Contract No. DEFG02-96ER45571. We gratefully acknowledge the computing resources provided by NPACI through the Texas Advanced Computing Center. We would also like to thank Dane Morgan for insightful observations. 
*Corresponding author. Electronic address: gceder@mit.edu

${ }^{1}$ J. M. Sanchez, F. Ducastelle, and D. Gratias, Physica A 128, 334 (1984).

${ }^{2}$ F. Ducastelle, Order and Phase Stability in Alloys (Elsevier Science, Amsterdam, 1991).

${ }^{3}$ D. de Fontaine, Solid State Phys. 47, 33 (1994).

${ }^{4}$ G. Ceder, M. Asta, and D. de Fontaine, Physica C 177, 106 (1991).

${ }^{5}$ A. Zunger, in Statics and Dynamics of Alloy Phase Transformations, NATO Advanced Study Institute, Series B: Physics, edited by P. E. Turchi and A. Gonis (Plenum Press, New York, 1994), p. 361 .

${ }^{6}$ M. Asta, R. McCormack, and D. de Fontaine, Phys. Rev. B 48, 748 (1993).

${ }^{7}$ B. Fultz et al., Phys. Rev. B 52, 3315 (1995).

${ }^{8}$ L. Anthony, J. K. Okamoto, and B. Fultz, Phys. Rev. Lett. 70, 1128 (1993).

${ }^{9}$ L. Anthony et al., Phys. Rev. Lett. 73, 3034 (1994).

${ }^{10}$ L. J. Nagel, L. Anthony, and B. Fultz, Philos. Mag. Lett. 72, 421 (1995).

${ }^{11}$ M. E. Manley and B. Fultz, Philos. Mag. B 80, 1167 (2000).

${ }^{12}$ A. van de Walle and G. Ceder, Phys. Rev. B 61, 5972 (2000).

${ }^{13}$ A. van de Walle, G. Ceder, and U. V. Waghmare, Phys. Rev. Lett. 80, 4911 (1998).

${ }^{14}$ V. Ozolinš̌, C. Wolverton, and A. Zunger, Phys. Rev. B 58, R5897 (1998).

${ }^{15}$ P. D. Tepesch et al., J. Am. Ceram. Soc. 79, 2033 (1996).
${ }^{16}$ V. Ozolinšs and M. Asta, Phys. Rev. Lett. 86, 448 (2001).

${ }^{17}$ M. Asta and V. Ozoliņš, Phys. Rev. B 64, 094104 (2001).

${ }^{18}$ C. Wolverton and V. Ozoliņš, Phys. Rev. Lett. 86, 5518 (2001).

${ }^{19}$ G. D. Garbulsky and G. Ceder, Phys. Rev. B 49, 6327 (1994).

${ }^{20}$ I. M. Robertson, J. Phys.: Condens. Matter 3, 8181 (1991).

${ }^{21}$ M. Sluiter, M. Weinart, and Y. Kawazoe, Europhys. Lett. 43, 183 (1998).

${ }^{22}$ M. Sluiter and Y. Kawazoe, Philos. Mag. A 78, 1353 (1998).

${ }^{23}$ M. H. F. Sluiter, M. Weinert, and Y. Kawazoe, Phys. Rev. B 59, 4100 (1999).

${ }^{24}$ P. Ghosez et al., Phys. Rev. B 60, 836 (1999).

${ }^{25}$ P. Giannozzi et al., Phys. Rev. B 43, 7231 (1991).

${ }^{26}$ A. van de Walle and G. Ceder, Rev. Mod. Phys. 74, 11 (2002).

${ }^{27}$ S. Wei and M. Y. Chou, Phys. Rev. Lett. 69, 2799 (1992).

${ }^{28}$ S. Wei and M. Y. Chou, Phys. Rev. B 50, 2221 (1994).

${ }^{29}$ K. Kunc and R. M. Martin, Phys. Rev. Lett. 48, 406 (1982).

${ }^{30}$ G. Kresse and J. Furthmüller, Comput. Mater. Sci. 6, 15 (1996).

${ }^{31}$ G. Kresse and J. Furthmüller, Phys. Rev. B 54, 11169 (1996).

${ }^{32}$ G. Kresse and D. Joubert, Phys. Rev. B 59, 1758 (1999).

${ }^{33}$ P. E. Blöchl, Phys. Rev. B 50, 17953 (1994).

${ }^{34}$ A. Zunger et al., Phys. Rev. Lett. 65, 353 (1990).

${ }^{35}$ D. Morgan, J. D. Althoff, and D. de Fontaine, J. Phase Equilib. 19, 559 (1998).

${ }^{36}$ P. D. Bogdanoff and B. Fultz, Philos. Mag. B 79, 753 (1999).

${ }^{37}$ G. Garbulsky, Ph.D. thesis, http://burgaz.mit.edu/ PUBLICATIONS/theses.php 